\title{
All Ceramic Inlays - Coming of Age
}

Ahmad Naeem ${ }^{1} \&$ Bashir Taseer ${ }^{2}$

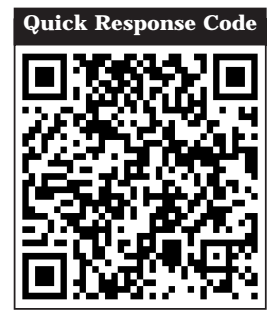

doi : $10.5866 / 2014.621550034$

1Senior Lecturer

Department of Prosthodontics, CPGIDS, Lucknow.

${ }^{2} \mathrm{PG}$ Student

Department of Oral Medicine,

CPGIDS, Lucknow.

\section{Article Info:}

Received: J anuary 12, 2014

Review Completed: February 10, 2014

Accepted: March 13, 2014

Available Online: J uly, 2014 (www.nacd.in)

(c) NAD, 2014 - All rights reserved

\section{Email for correspondence:}

naeem_bds@yahoo.co.in

\begin{abstract}
:
In the past decade and a half there has been an explosion in the introduction of restorative materials and techniques for the restoration of posterior teeth. The primary impetus for this explosion has been society's fascination with aesthetics in general, and a concomitant desire to eliminate metallic restorations. Here a young male patient was treated with a highly wear resistant pressableceramic inlay (CERGO pressable ceramic) that enhanced the esthetic value.
\end{abstract}

Key words: ceramic, inlays, pressable inlays

\section{INTRODUCTION:}

Esthetics al ternatives to the cast gold inlays and amalgam fillings include glass ionomer cements, hybrid ionomers, direct composites, compositeinlays and ceramic inlays. The first attempt to use esthetic inlays was described at the end of nineteenth century. ${ }^{1}$ This trend achieved larger acceptance with the introduction of restorative materials bonded to natural teeth substrate. An indirect esthetic adhesive restoration, that is ceramic inlays have become clinically acceptable restorations for posterior teeth with extended coronal destruction.
In 1988 a survey in USA showed that morethan $50 \%$ of those individuals questioned with regard to their attitude to tooth colored restorations were not aware that such materials could be used for posterior tooth. ${ }^{2}$ Although the appearance of posterior teeth was judged to be either somewhat $(51 \%)$ or very (37\%) important, only a small percentage (17\%) indicated that they would have their posterior restorations replaced with resin. When patients who had previously received posterior composite restorations, weresurveyed, $75 \%$ were satisfied with the result and $96 \%$ stated that they would request 
a tooth colored posterior restoration if required in the future, even though $18 \%$ disliked the procedure because of increased time taken. ${ }^{3}$ The possibilities of innovative uses of esthetic materials are existing and almost unlimited.

\section{Esthetic restorative systems and materials}

Currently there are several tooth colored restorative systems available for the restoration of cavities in the posterior teeth. They aresummarized as follows, based on placement techniques:

\section{DIRECT PLACEMENT RESTORATIONS}

\section{A- Composite resins}

The introduction of this filled resin material in 1962 became the basis for the restorations that are generally termed composites. Composites are presently the most popular tooth colored restorative materials, having completely replaced silicate cement and partially silver amalgam. Composites and acid-etch technique represent two major advances. Adhesive materials that form stronger bonds to enamel and dentin layer has further simplified restorative technique.

Composites can be used on any part of the tooth structure with considerations towards isolation, occlusion and operative factors. The primary contraindications for use of composites as a restorative material are; if operating site cannot be isolated from contamination by oral fluids, or if all the occlusal points are on the restoration and also if the operator is not confident enough to use it.

\section{B- Quartz inserts - composite resin}

In theory, the properties of the inserts are closer to the tooth than that with composite. Using this knowledge, first considered in the mid 1980, betaquartz inserts made of lithium alumino-silicateglass combined with modified oxides and treated with silane coupling agent, which are placed within composite restorations.

Advantages of such inserts include: reduction in polymerization shrinkage, increased dimensional stability, chemical and mechanical bonding to composite resin $\&$ the disadvantages include cost of material and time consumed.

\section{INDIRECT PLACEMENT RESTORATIONS}

In an attempt to overcome some of the problems associated with direct placement posterior composite techniques, in particular polymerization shrinkage and control of anatomic form, esthetic inlay systems utilizing composite resins or porcelain have been devel oped and have a scope for future devel opment.

\section{Indications}

Esthetics: Indirect tooth colored restorations are for areas of esthetic importance for the patient. Large defects or previous restorations: large class I and class II defects or replacement of large existing compromised restorations, especially those that are wide faciolingually and require cuspal coverage.

Economic factors: Some patients desire best dental treatment available, regardless of the cost. Indirect tooth colored restorations may be indicated, not only for large defects, but al so for moderate sized restorations that might otherwise be restored with direct restorative material.

\section{Contraindications}

Heavy occlusal forces: Ceramic restorations may fracture when they lack bulk or are subjected to excessive occlusal stress, as in patients who have bruxing or clenching habits.

Inability to maintain dry field: Adhesive techniques for indirect restorations require near perfect moisture control to ensure successful long term clinical results. Deep sub gingival preparation: not an absolute contraindication, but be avoided. These margins are difficult to record with an impression and are difficult to finish. ${ }^{4}$

\section{TYPES OF ESTHETIC INLAYS}

\section{a) Composite inlays}

The physical properties of composite restorations are improved when the composite is free of voids, and the resin matrix is 
maximally polymerized. Generating dense, well cured restorations is best accomplished in the dental laboratory using devices that polymerize the composite under pressure, vacuum, inert gas, intenselight, heat and combination of these conditions.

\section{b) Ceramic inlays}

Ceramic inlays have become popular not only because of patients demand for esthetics, durable restorative materials, but also because of recent improvements in the materials, fabrication techniques, and bonding systems.

\section{Various ceramic materials used are:}

\section{Feldspathic porcelain inlays}

Dental porcelains are partially crystalline minerals (feldspar, silica, alumina) dispersed in a glass matrix. ${ }^{5}$ Porcelain restorations are made from finely ground ceramic powders that are mixed with distilled water or a special liquid, shaped into a desired form, then fired and fused together to form a translucent material that looks like tooth structure.

\section{Hot pressed glass ceramics}

In 1968, it was discovered that certain glasses could be modified with nucleating agents and upon heat treatment, be changed into ceramics with organized crystalline forms. Such "glass ceramics" were stronger, had a higher melting point than non crystalline glass, and had variable coefficient of thermal expansion.

\section{Machinable or CAD CAM}

Rapid improvements in technology, have spurned several computerized devices that can fabricate ceramic inlays and onlays from high quality ceramics in matter of minutes. Some CAD CAM systems are very expensive laboratory based units requiring the submission of impression or working cast of a prepared tooth. The CEREC system was the first commercially available CAD CAM system developed for the rapid chair side design and fabrication of ceramic restorations.

\section{CASE REPORT}

A young male patient reported to the department of Endodontics, Rural Dental College, Loni, Maharashtra with a chief complaint of food lodgment in distal aspect of both the mandibular first molars. On examination a composite restoration was seen in relation to 46 (DO) having inadequate contact with adjacent tooth, and a cement filling with 36 (DO) which had been dislodged partially (Figure 1).

After radiographic assessment and evaluation of patient's needs, it was planned to replace both of the previous restorations with all ceramic pressable inlays (CERGO pressable ceramic). Tooth preparation was done keeping in mind the depth and restorations to be replaced were completely removed. After theimpression and cast preparation, the wax patterns were fabricated and sprued for investing. Multimat touch - press system accomplished the procedure to process ceramic inlays.

Casted ceramic inlays were then cleared of the investment with air abrasion. Sprues were cut and the inlays were fitted onto the cast for necessary corrections. Stains and gl oss applied on the occlusal surface and fired. After trial seating, fit and contact points were evaluated and finally cementation of both the inlays was done with Rely X U 100 self adhesive universal resin cement (Figures 2-5).

\section{DISCUSSION}

Marginal integrity is one of the most important criteria's when restoration success is evaluated. Ceramic inlays superior marginal integrity is confirmed in an in vitro study by Mehl A in 1996. Because adhesive inlays are inserted into cavities with a resin cement, the luting gap is always susceptible to increased wear as mechanical properties of the resin cement is inferior compared with highly wear resistant ceramic inlays.

Loss of marginal integrity can be caused at seline polymerization shrinkage or removing of cement flashes with blunt instruments. Premolars 


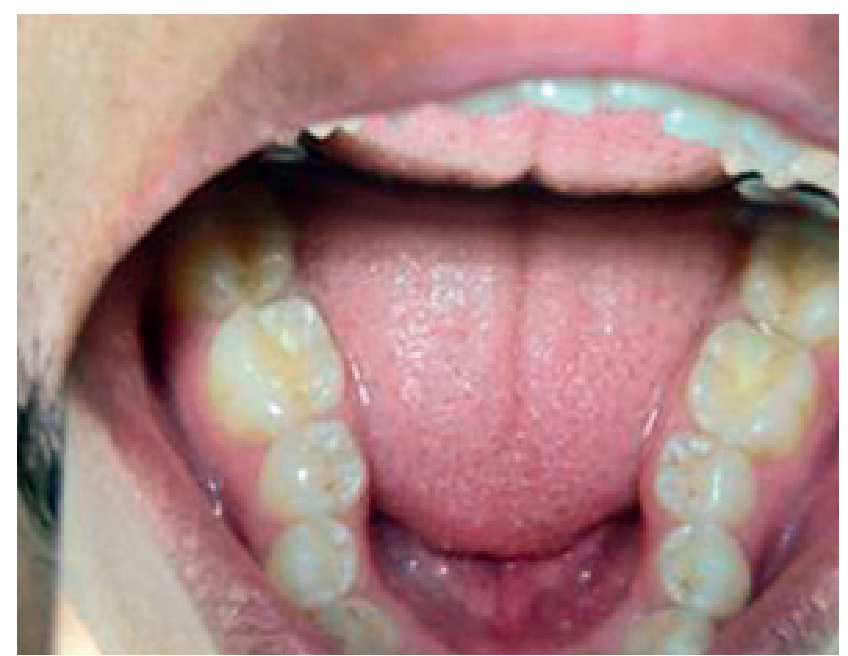

Figure 1: Pre operative photograph of 36 and 46.

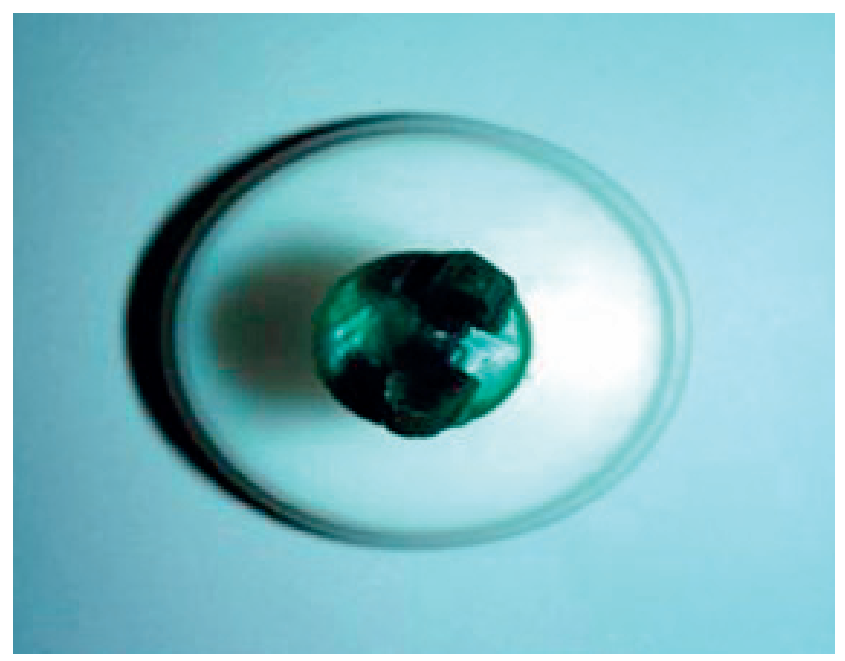

Figure 3: Wax pattern

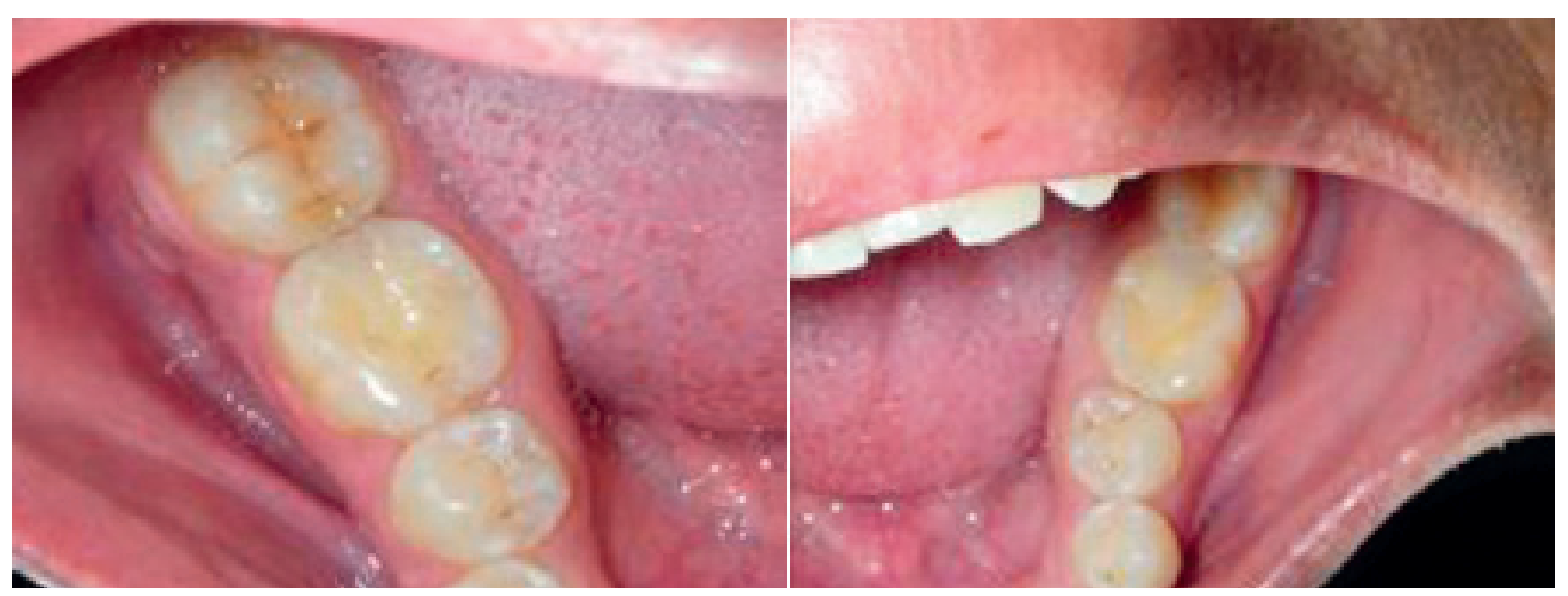

Figure 5: Inlay cementation with $36 \& 46$
Figure 2: Die preparation

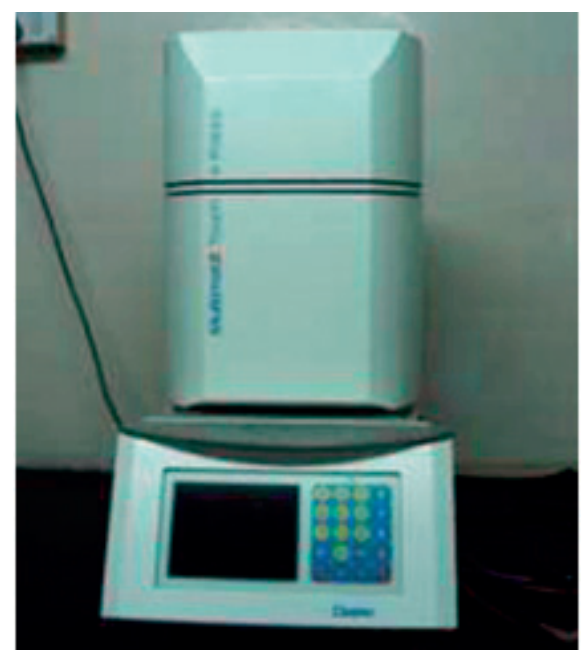

Figure 4: Multimat 2 touch - press (Dentsply) 
usually offer more favorable conditions for adhesive inlays than molars. Cavities are usually smaller, the effect of chewing forces is less intense, and access for the dental treatment is easier. Dental treatment also plays an important role, because the adhesive insertion technique is sensitive to the handling of materials and the dentist's technique. ${ }^{6}$ Hencetaking all this into consideration, the least technique sensitive with accepted bond strength luting cement was selected (Rely X U 100 self-adhesive universal resin cement), etching and use of primer and/or bonding as pretreatment of tooth substrate are not necessary.

Only a few systems have been successful for the restoration of molars, and additional factors such as adequate preparation depth and cementation can outweigh material considerations. It has been proven that ceramic inlays have $94 \%$ survival probability after 57 months of clinical service. ${ }^{7}$

\section{CONCLUSION}

With the ceramic and composite material showing diverse physical properties, many aspects of their associated techniques show common features, for example, cavity preparation, indication for use and luting procedure. However, a main indication for the use of ceramic restoration in cases requiring a high level of wear resistance. While composite inlays are generally consi der ed to be more user friendly and thereby less costlier than ceramic inlays. Nevertheless, it may be anticipated that future trends will show increasing demand for techniques, such as esthetic inlays, alongside the refinement of new techniques such as those provided by computer aided design and manufacture.

\section{REFERENCES}

1. Donovan TE, Chee WW. Conservative direct restorations for posterior teeth. Cast versus bonded ceramic. Dent Clin North Am 1993; 3:433-443

2. Davis E L, Laura J C. Determination of demand for posterior resin restoration. J Prosthet Dent 1998; 59: 242-248

3. Burke F. Patient acceptance of posterior composite restorations. Dent Update 1989; 16: $114-120$

4. Burke EJ, Qualtrough A. Aesthetic inlays: composite or ceramic? J Br Dent J . 1994 J an 22; 176(2): 53-60

5. Anusavice KJ. Phillip's science of dental materials, Philadelphia 1996, WB Saunders, $10^{\text {th }}$ edition.

6. Scheibenbogen. One year clinical evaluation of composite and ceramic inlays in posterior teeth. J Prosthet Dent 1998; 80(4): 410-416

7. Lange RT, Pfeiffer $P$. Clinical evaluation of ceramic inlays compared to composite restorations. Oper Dent 2009; 34(3): 263-272.

\section{Gain quick access to our journal online View our journal at www.nacd.in}

